\title{
POTENSI EKSPOR SENTRA KERAJINAN KERAMIK PEJATEN
}

\author{
Ni Putu Yuria Mendra ${ }^{*}$, Tjokorda Istri Praganingrum², \\ Ni Putu Sintya Saraswati ${ }^{3}$, I Made Suryawan ${ }^{4}$ \\ ${ }^{1 *}$ Program Studi Akuntansi, Fakultas Ekonomi, Universitas Mahasaraswati \\ ${ }^{2}$ Program Studi Teknik, Fakultas Teknik, Universitas Mahasaraswati \\ ${ }^{3}$ Program Studi Manajemen, Fakultas Ekonomi, Universitas Mahasaraswati \\ ${ }^{4}$ Program Studi Hukum, Fakultas Hukum, Universitas Mahasaraswati \\ ${ }^{*}$ Corresponding author : \\ Email : yuriamendra@gmail.com
}

Diterima 2 November 2018, Disetujui 7 November 2018

\begin{abstract}
ABSTRAK
Bali dikenal sebagai daerah seni dan tujuan wisata nasional maupun internasional memiliki beraneka ragam bentuk kerajinan seni salah satunya adalah usaha kerajinan keramik. Dewasa ini peminat keramik semakin bertambah, baik dari kalangan bawah maupun kalangan atas, sehingga hal ini mendorong UKM yang bergerak di bidang keramik berupaya meningkatkan usahanya agar dapat meraih pangsa pasar baik lokal maupun internasional. UKM dalam kegiatan ini yaitu Durya Keramik dan Mika Keramik. Berdasarkan hasil observasi yang telah dilakukan tim ternyata kedua UKM memiliki permasalahan yaitu 1) Peralatan dalam proses produksi masih tradisional dan banyak peralatan yang rusak dan; 2) Minim dalam teknik pewarnaan keramik (glasir); 3) Tidak memiliki katalog; 4) Belum memiliki website; 5) Dalam tahapan produksi belum menerapkan sesuai standard operation procedur (SOP); dan 6) Tidak memperhatikan kesehatan dan kebersihan dalam bekerja. Solusi yang ditawarkan pada kedua mitra yaitu 1) Peremajaan peralatan dengan melakukan pembelian peralatan berupa mesin putar listrik dan plat oven; 2) Pelatihan teknik pewarnaan keramik (glasir); 3) Pembuatan katalog; 4) Pembuatan website; 5) Penerapan standard operation procedur (SOP); dan 6) Pengadaan masker dan apron (celemek) bagi pekerja. Melalui kegiatan ini dapat membantu UKM meningkatkan kapasitas dan kualitas produksi yang akhirnya dapat meningkatkan profitabilitas dari usaha tersebut.
\end{abstract}

Kata kunci: UKM, Keramik, Ekspor, Pembinaan, Pendampingan

\begin{abstract}
Bali is known as an art area and national and international tourism destinations have a variety of forms of art crafts, one of which is a ceramic handicraft business. Today, ceramic enthusiasts are increasingly growing, both from the lower and upper classes, so this encourages UKm engaged in ceramics to strive to increase their business in order to gain market share both locally and internationally. UKM in this activity are Durya Keramik and Mika Keramik. Based on observations made by the team, it turns out that the two UKM have problems, namely 1) Equipment in the production process is still traditional and many equipment is damaged and; 2) Lack in ceramic coloring techniques (glaze); 3) Do not have a catalog; 4) Don't have a website; 5) In the production stage, it has not applied according to the standard operation procedure (SOP); and 6) Not paying attention to health and cleanliness at work. The solutions offered to both partners are 1) Rejuvenation of equipment by purchasing equipment in the form of electric rotary machines and oven plates; 2) Training in ceramic coloring techniques (glaze); 3) Cataloging; 4) Website creation; 5) Implementation of standard operating procedures (SOP); and 6) Procurement of masks and aprons for workers. Through this activity can help SMEs increase the capacity and quality of production which ultimately can improve the profitability of the business.
\end{abstract}

Keywords: UKM, Ceramics, Export, Coaching, Assistance

\section{PENDAHULUAN}

Ekspor adalah salah satu kegiatan ekonomi yang dilakukan dengan cara penjualan atau mengeluarkan barang dari dalam negeri dan dikirimkan ke negara lain. Biasanya perdagangan ini dilakukan bila suatu negara menghasilkan barang tersebut dalam jumlah yang besar. Saat hal itu terjadi, negara tersebut dapat mengirimkannya ke luar negeri karena kebutuhan di dalam negeri sudah terpenuhi. Apabila kita melakukan kegiatan ekspor dalam skala yang besar, pengirimannya harus dibantu oleh bea 
cukai di negara penerima dan pengirimnya. Ada beberapa syarat dan ketentuan yang harus dipenuhi dalam kegiatan ini agar lebih aman. Karena setiap negara memiliki syarat dan ketentuan yang berbeda-beda. Tujuan kegiatan ekspor ini adalah untuk membuat dunia usaha menjadi lebih kondusif. Selain itu hal ini juga bertujuan mengendalikan harga produk ekspor yang ada di dalam negeri. Di sisi lain hal ini juga dapat menjaga kurs valuta asing agar dalam keadaan stabil dan juga bermanfaat untuk memperluas pasar bagi Indonesia dan menambah devisa.

Salah satu potensi ekspor Indonesia adalah usaha kerajinan keramik. "Kualitas produk keramik yang dihasilkan industri keramik di dalam negeri tidak kalah dengan negara-negara lain di dunia. Buktinya, Indonesia merupakan salah satu produsen terbaik di dunia dan menduduki peringkat keenam dunia. Industri keramik di Indonesia yang telah berkembang selama lebih dari 30 tahun merupakan salah satu industri unggulan dengan ketersediaan bahan baku melimpah. "Prospek industri keramik nasional dalam jangka panjang cukup baik seiring dengan pertumbuhan pasar dalam negeri yang terus meningkat,

Bali dikenal sebagai daerah seni dan tujuan wisata nasional maupun internasional memiliki beraneka ragam bentuk kerajinan seni salah satunya adalah usaha kerajinan keramik. Dewasa ini peminat keramik semakin bertambah, baik dari kalangan bawah maupun kalangan atas, sehingga hal ini mendorong UKM yang bergerak di bidang keramik berupaya meningkatkan usahanya agar dapat meraih pangsa pasar baik lokal maupun internasional. Sentra-sentra usaha kerajinan keramik yang ada di Pulau Bali yaitu berpusat di Kabupaten Tabanan. Pejaten adalah salah satu Desa di Kabupaten Tabanan yang merupakan sentra usaha pembuatan keramik. Kerajinan keramik menjadi prospek yang menjanjikan bagi pasar internasional karena sangat diminati oleh wisatawan khususnya wisatawan mancanegara dan sebagai salah satu sumber devisa bagi Bali.

Melihat potensi dan data perkembangan pemasaran ekspor kerajinan keramik tersebut, sangatlah mungkin apabila dapat ikut berperan serta dalam pengembangan kerajinan keramik khususnya kearah yang lebih maju. Pengembangan dan pendampingan dilakukan baik dari segi kualitas dan kuantitas, desain, kesehatan dan kebersihan, serta segi manajemen dan pemasaran. Durya Keramik dan Mika Keramik merupakan salah satu dari sekian banyak perajin keramik yang ada di Desa Pejaten. Durya Keramik sebagai Mitra 1 dan Mika Keramik sebagai Mitra 2 sama-sama berlokasi di $\mathrm{Br}$ Pamesan, Pejaten, Kediri, Tabanan.
Durya Keramik sebagai Mitra 1 yang dimiliki oleh I Made Durya awal usahanya yaitu Tahun 1986 yang mana masih dibina oleh Orang Perancis, kemudian karena sudah dianggap mampu, maka Pada Tahun 1992 usaha ini dikelola sendiri oleh I Made Durya. Produk yang dihasilkan beragam yaitu meliputi tempat dupa, tempat aromatherapi, gelas, piring hias, mangkuk, souvenir, dan guci yang harga berkisar Rp 50.000 sampai $\mathrm{Rp} 300.000$ dan dipasarkan di pasar lokal dan pasar internasional seperti Perancis, Amerika, Australia, dan New Zealand. Berbagai kendala yang dialami usahanya yaitu baik dari peralatan masih tradisional dan sudah mulai rusak serta tidak layak pakai, layout ruang produksi yang tidak sistematis sehingga proses produksi tidak berjalan efektif, gudang penyimpanan yang tidak tertata rapi karena minimnya pengetahuan tentang manajemen stock barang, serta minimnya pengetahuan tentang teknik glasir (pewarnaan keramik).

Mika Keramik sebagai Mitra 2 dimiliki oleh $\mathrm{Ni}$ Luh Nyoman Kalpikawati.Pada awalnya Ni Luh Nyoman Kalpikawati beserta suami I Nyoman Miasa adalah pegawai yang bekerja di Durya Keramik, karena dianggap sudah mampu untuk memulai usaha sendiri, maka pada Tahun 2006 mulai berusaha sendiri.Produk keramik andalan Mika keramik yaitu Teko Kerawang yang didesain sendiri oleh I Nyoman Miasa yaitu suami dari $\mathrm{Ni}$ Luh Nyoman Kalpikawati. Produk keramik yang dijual yaitu meliputi tempat dupa, oil banner, gelas, piring hias, mangkuk, teko, dan souvenir yang kisaran harga yaitu mulai dari harga Rp 3.000 sampai Rp 300.000 dan dipasarkan di pasar lokal dan pasar internasional seperti Amerika, Australia dan Jepang. Dalam usahanya Mika Keramik mengalami permasalahan khususnya seperti peralatan produksi yang sudah mulai rusak karena melampaui masa pakai, minimnya pengetahuan tentang teknik glasir (pewarnaan keramik), Belum memiliki sarana pemasaran yang baik.

Berdasarkan hasil observasi dan wawancara yang telah dilakukan tim ternyata kedua mitra tersebut memiliki keberlanjutan usaha yang sangat menjanjikan dan sangat membutuhkan pembinaan dan pendampingan usaha serta bantuan secara berkesinambungan sehingga dapat meningkatkan profitabilitas dari usaha tersebut, yang mana merupakan potensi ekspor bagi Tabanan khususnya dan Bali pada umumnya. Berdasarkan kesepakatan permasalahan utama kedua mitra antara lain:

1. Proses produksi kerajinan masih
menggunakan peralatan tradisional serta
keterbatasan alat yang mengakibatkan
pemenuhan target penyelesaian produk


pesanan menjadi terkendala karena produktivitas dan waktu proses relatif lama.

2. Produk kerajinan keramik sering kalah bersaing dengan produk lainnya karena minimnya variasi desain. Selain itu masih minimnya pengetahuan dalam teknik pewarnaan keramik (glasir).

3. Tidak memiliki katalog produk sehingga konsumen tidak memiliki referensi tentang produk apa saja yang dihasilkan.

4. Belum memiliki sarana promosi atau pemasaran online, yang mana dengan pemasaran online dapat memperluas jaringan pemasaran

5. Pada bagian proses produksi belum melaksanakan standard operation procedur (SOP) pada tiap tahapan produksi.

6. Dalam proses produksi, tenaga kerja belum memperhatikan kesehatan dan kebersihan dalam proses produksi. Dalam proses produksi akan banyak ada debu dan kotoran yang menempel, akan tetapi tenaga kerjanya tidak memamaki masker dan apron (celemek). Masker digunakan untuk menutup hidung, supaya debu tidak terhirup, sedangkan apron (celemek) digunakan agar pakaian yang digunakan tenaga kerja tidak kotor.

7. Pengelolaan manajemen yang dilakukan masih tradisional, masih belum menggunakan manajemen dan pembukuan yang baik. Pembukuan yang digunakan selama ini masih sangat minim yang hanya meliputi buku catatan yang digabung yang berisikan catatan pembelian bahan baku, pemesanan, order dan penjualan order, pencatatan pembayaran upah, sehingga belum memperhatikan perhitungan harga pokok produk.

Tujuan dari program Pengembangan produk ekspor (PPPE) adalah untuk memberikan pengadaan alat produksi, pendampingan, pelatihan baik dalam hal produksi maupun manajemen dan pembukuan yang dibutuhkan oleh kedua mitra untuk memperlancar usaha yang dimiliki masing-masing.

\section{METODE PELAKSANAAN}

\footnotetext{
Berdasarkan uraian prioritas permasalahan yang dihadapi maka metode pelaksanaan yang dilakukan adalah sebagai berikut:

1. Pembelian peralatan bagi Mitra 1 dan Mitra 2 yaitu mesin putar listrik dan plat oven, sehingga dengan pembelian peralatan dapat menambah kuantitas dan kualitas produk.

2. Memberikan pelatihan dan pendampingan teknik glasir (pewarnaan keramik) oleh tim ahli di bidang seni pewarnaan untuk Mitra 1 dan Mitra 2.
}

3. Membantu dalam merancang dan membuat katalog produk untuk Mitra 1 dan Mitra 2. Pembuatan katalog produk bertujuan untuk membantu mitra dalam memperkenalkan desain produk yang dimiliki masing-masing mitra dan memudahkan konsumen dalam memilih produk apa saja yang tersedia.

4. Merancang website untuk Mitra sehingga dapat memperkenalkan dan memperluas jaringan pemasaran. Kemudian dilakukan pendampingan dalam mengoperasikan website oleh tim yang ahli di bidangnya.

5. Pembuatan dan Penerapan standard operation procedur (SOP) pada tiap tahapan produksi, bagi Mitra 1 dan Mitra 2.

6. Melakukan pengadaan masker dan apron (celemek) bagi tenaga kerja untuk Mitra 1 dan Mitra 2 agar terjaga kesehatan dan kebersihan tenaga kerjanya

7. Pelatihan dan pendampingan pembukuan dan akuntansi untuk Mitra 1 dan Mitra 2. Kegiatan pelatihan ini dengan cara melatih program akuntansi. Gunanya mempermudah Mitra melakukan pembukuan.

\section{HASIL DAN PEMBAHASAN}

Beberapa kegiatan yang telah dilaksanakan kepada kedua mitra yaitu Durya Keramik dan Mika Keramik anatara lain:

1. Peremajaan dan Penambahan Peralatan Produksi.

Proses produksi kerajinan masih menggunakan peralatan tradisional seperti meja putar tradisional sehingga dalam pengerjaan memerlukan waktu yang relatif lama. Perkakas yaitu plat pada mesin oven banyak yang patah dan mulai rusak, sehingga apabila ada pesanan khusus, tidak bisa mengerjakan dan mengambil order, karena hasilnya nantinya tidak baik dan tidak layak ekspor. Keterbatasan alat mengakibatkan pemenuhan target penyelesaian produk pesanan menjadi terkendala karena produktivitas dan waktu proses relatif lama. Berdasarkan hal tersebut maka tim memberikan bantuan peralatan produksi berupa meja putar keramik listrik kepada Durya Keramik (Mitra1) dan plat oven kepada Mika Keramik (Mitra 2) sehingga mitra dapat menerima order pesanan khusus, sehingga bisa meningkatkan produksi dan layak ekspor. Bagi Durya Keramik, penggunaan meja putar listrik dapat mempercepat proses pembuatan keramik yang awalnya dengan meja putar listrik mebutuhkan waktu 1 jam, kini bisa dipercepat menjadi 30 menit. Adanya plat oven bagi Mika Keramik sangat membantu, sehingga kini bisa mengambil pesanan piring 
yang mana awalnya selalu menolak pesanan karena plat oven banyak yang rusak.

\section{Gambar 1 \\ Penyerahan Meja Putar Listrik Kepada Durya Keramik}

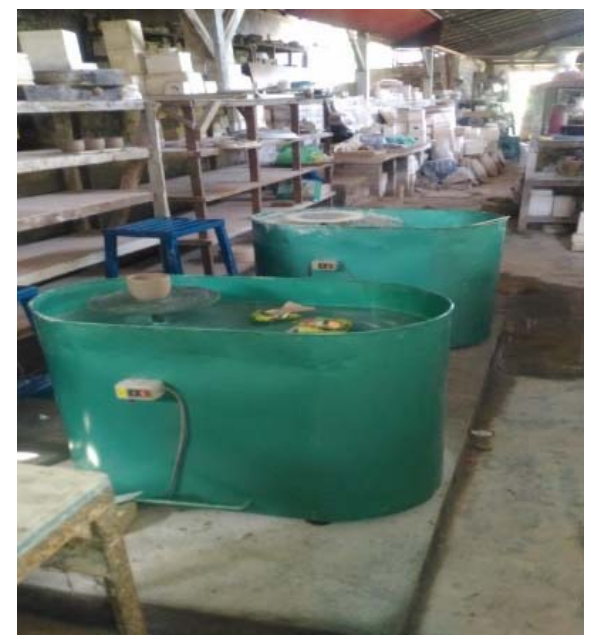

Sumber: Dokumen Peneliti (2018)

\section{Gambar 2 \\ Penyerahan Plat Oven Kepada Mika Keramik}

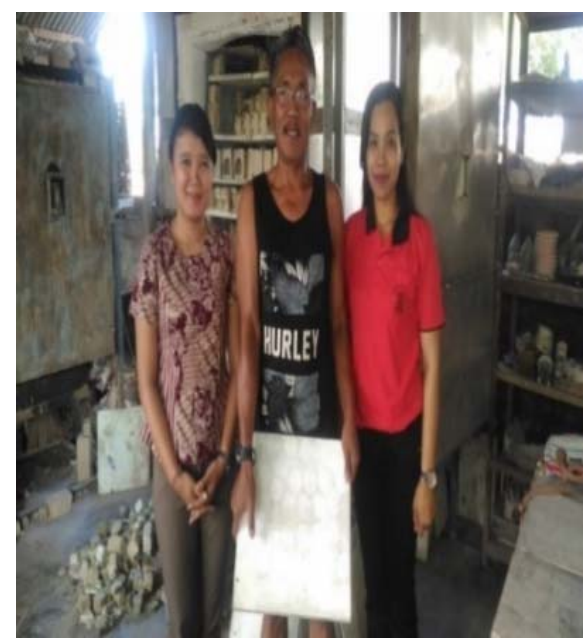

Sumber: Dokumen Peneliti (2018)

2. Pelatihan dan Pendampingan Teknik Glasir. Pelatihan dan pendampingan teknik glasir (pewarnaan keramik) diberikan oleh tim ahli di bidang seni pewarnaan untuk Mitra 1 dan Mitra 2. Dengan pemberian pelatihan diharapkan mitra memiliki kreasi yang lebih baik dalam teknik pewarnaan, sehingga produk menjadi lebih berkualitas. Adanya teknik glasir bagi Durya Keramik dan Mika Keramik adalah mereka bisa menciptakan produk dengan warna yang bagus sehingga kualitas produk, nilai estetisnya dan nilai jual menjadi lebih mahal. Adapun keramik yang khas adalah Teko Kerawang dan Piring Daun.

\section{Gambar 3}

Keramik Teko Kerawang Dengan Teknk Glasir Baru

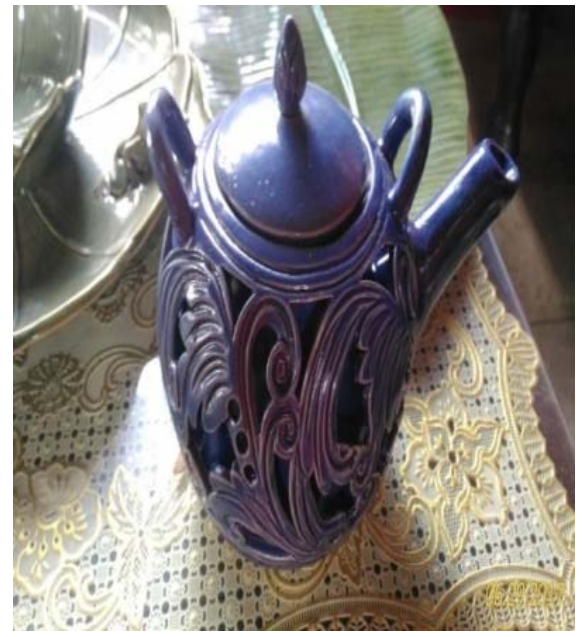

Sumber: Dokumen Peneliti (2018)
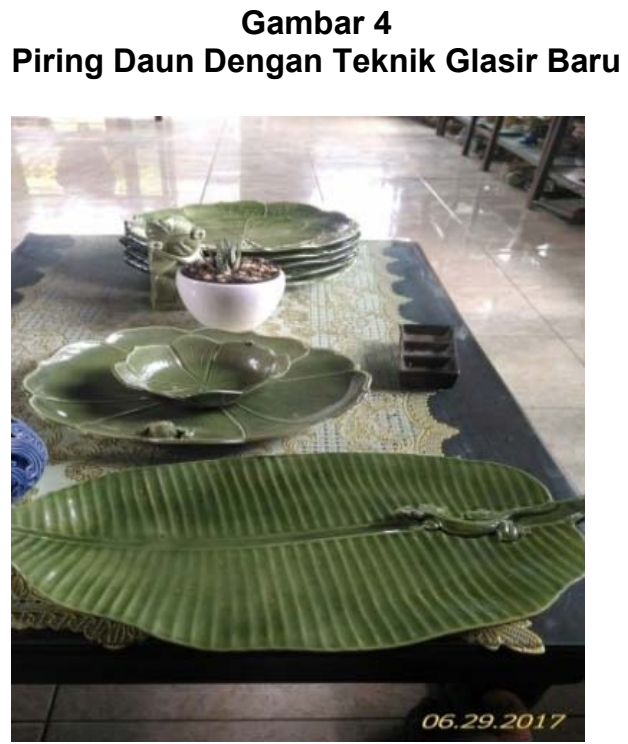

Sumber: Dokumen Peneliti (2018)

3. Pembuatan Katalog Produk

Membantu dalam merancang dan membuat katalog produk untuk Mitra 1 dan Mitra 2. Pembuatan katalog produk bertujuan untuk 
membantu mitra dalam memperkenalkan desain produk yang dimiliki masing-masing mitra dan memudahkan konsumen dalam memilih produk apa saja yang tersedia. Dalam katalog berisi foto keramik dengan masing masing nama, sehingga pengunjung dan pembeli lebih mudah untuk melakukan pemesanan.

4. Pembuatan Website

Merancang website untuk Mitra sehingga dapat memperkenalkan dan memperluas jaringan pemasaran. Kemudian dilakukan pendampingan dalam mengoperasikan website oleh tim yang ahli di bidangnya, hal ini bertujuan agar produk yang dihasilkan mitra bisa dikenal oleh masyarakat baik lokal maupun internasional.

5. Pembuatan dan Penerapan standard operation procedur (SOP) pada tiap tahapan produksi. SOP dibuat untuk setiap tahapan produksi dengan tujuan antara lain:

a. Sebagai standar cara yang dilakukan karyawan dalam menyelesaikan pekerjaan dalam menyelesaikan tugasnya

b. Mengurangi tingkat kesalahan dan kelalaian yang mungkin dilakukan oleh karyawan dalam melaksanakan tugas

c. Meningkatkan efisiensi dan efektifitas pelaksanaan tugas dan tanggung jawab individu karyawan dan usaha yang dijalankan secara keseluruhan

d. Membantu karyawan menjadi lebih mandiri dan tidak tergantung pada intervensi manajemen.

\section{Gambar 5}

SOP Untuk Durya Keramik

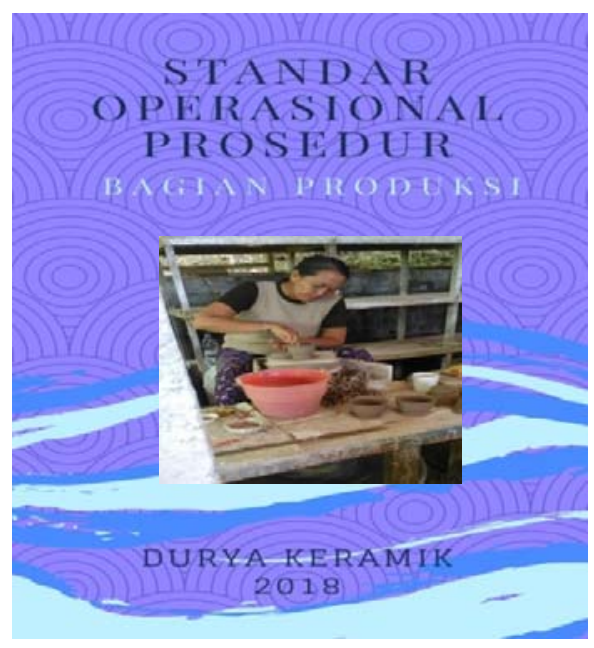

Sumber: Dokumen Peneliti (2018)

\section{Gambar 6 SOP Untuk Mika Keramik}

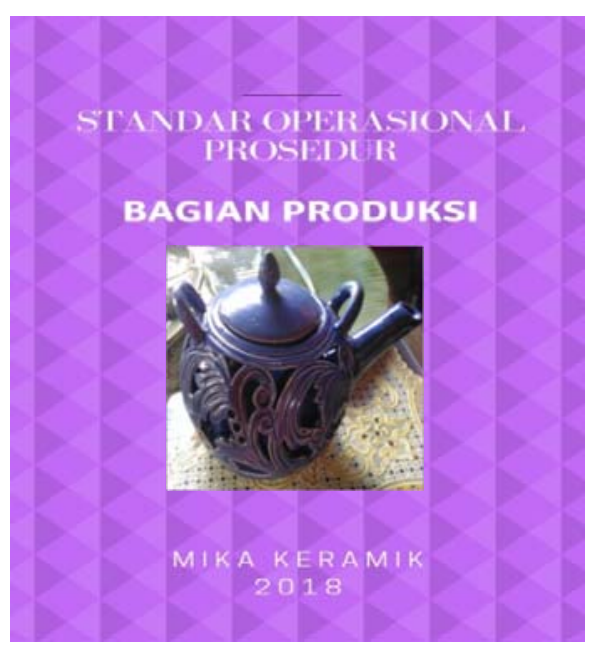

Sumber: Dokumen Peneliti (2018)

6. Pengadaan Masker dan Apron (Celemek)

Melakukan pengadaan masker dan apron (celemek) bagi tenaga kerja untuk Mitra 1 dan Mitra 2 agar terjaga kesehatan dan kebersihan tenaga kerjanya. Penggunaan masker berguna melindungi dari debu pengolahan keramik dan aroma dari bahan campuran keramik. Penggunaan celemek (apron) berguna melindung pakaian para pekerja agar tidak kotor akibat tanah liat.

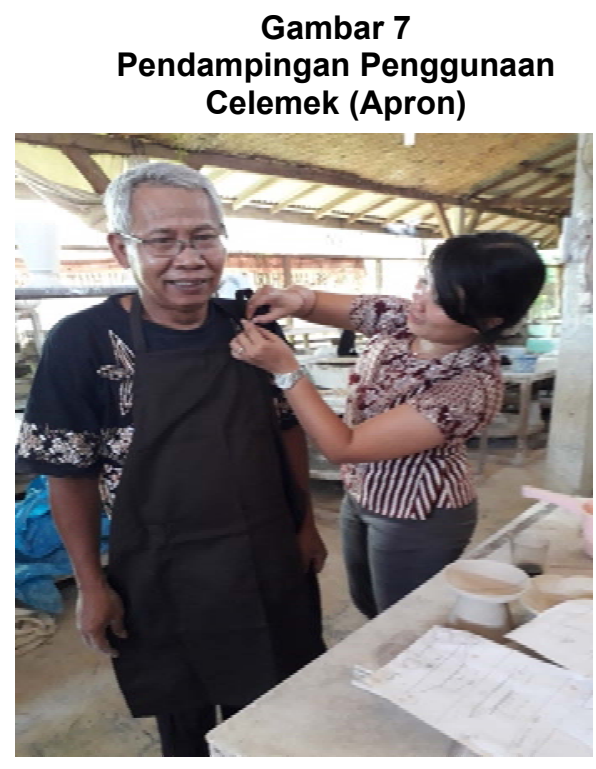

Sumber: Dokumen Peneliti (2018) 
7. Pelatihan dan Pendampingan Pembukuan Pengelolaan manajemen yang dilakukan masih tradisional, masih belum menggunakan manajemen dan pembukuan yang baik. Pembukuan yang digunakan selama ini masih sangat minim yang hanya meliputi buku catatan yang digabung yang berisikan catatan pembelian bahan baku, pemesanan, order dan penjualan order, pencatatan pembayaran upah, sehingga belum memperhatikan perhitungan harga pokok produk. Oleh karena itu tim memberikan pelatihan dan pendampingan tentang manajemen dan pembukuan, sehingga mitra bisa membuat laporan harga pokok produksi dan laporan keuangan sederhana. Dengan laporan yang dibuat, maka mitra mengetahui berapa keuntungan yang dimiliki secara pasti.

\section{SIMPULAN DAN SARAN}

Pelaksanaan kegiatan pengabdian memberikan dampak yang besar terhadap kualitas produk dan produktivitas kerja untuk mitra usaha serta memberikan manfaat yang berdampak langsung yaitu adanya motivasi dan semangat yang tinggi dari pengelola mitra dalam memajukan usahanya sehingga nantinya mitra mampu memproduksi produk yang berkualitas dan akhirnya berkontribusi terhadap peningkatan kuantitas produksi dan omzet masing- masing mitra.

\section{UCAPAN TERIMA KASIH}

Tim Program Pengembangan Produk Ekspor (PPPE) mengucapkan terimakasih yang sebesar-besarnya kepada seluruh pihak yang telah membantu menyukseskan pelaksanaan kegiatan PPPE diantaranya Direktorat Riset dan Pengabdian Masyarakat, Direktorat Jenderal Penguatan Riset dan Pengembangan Kementerian Riset, Teknologi, dan Pendidikan Tinggi. Terimakasih kepada LPPM Universitas Mahasaraswati Denpasar, kedua mitra yaitu Durya Keramik (Mitra 1) dan Mika Keramik (Mitra 2) serta tim dosen. Akhir kata, semoga Program Pengembangan Produk Ekspor (PPPE) dapat memberikan manfaat baik dari segi kualitas maupun kuantitas bagi kedua mitra usaha keramik dan bermanfaat bagi program pengabdian kepada masyarakat berikutnya.

\section{DAFTAR RUJUKAN}

Anonim. 2011. Kitab UU HaKI (Hak atas Kekayaan Intelektual) Dilengkapi dengan Penjelasan. Yogyakarta: Permata Press.
Anonim. 2014. Undang Undang UMKM (Usaha Mikro Kecil dan Menengah). Yogyakarta: Pustaka mahardika

Budiarto, Rachmawan. Susetyo Putera. Hempry Suyatno dan Puji Astuti. 2015. Pengembangan UMKM antara Konseptual dan Pengalaman Praktis. Yogyakarta: Gadjah Mada University Press.

Fajar, Mukti, ND. 2016. UMKM di Indonesia Persepektif Hukum Ekonomi. Cetakan Pertama. Yogyakarta: Pustaka Pelajar

Hansen, Don R. and Mowen Maryanne M. 2005. Akuntansi Manajemen. Buku 1. Edisi 7. Jakarta: Salemba Empat.

2005. Akuntansi Manajemen. Buku 2. Edisi 7. Jakarta: Salemba Empat

Kamaruddin Asep, 2006. Hambatan lusaha lkecil dan Menengah dalam Kegiatan Ekspor, Jurnal Pengembangan Koperasi dan UKM, KemenKop RI, Jakarta. Hal.101

Kamaludin, 2011. Manajemen Keuangan Teori dan Aflikasi, Mandar Maju, Bandung.

Nitisusatro, Mulyadi. 2012. Kewirausahaan dan Manajemen Usaha Kecil. Cetakan kedua. November. Bandung: Alfabeta.

Soeherman, Bonnie. 2010. Membangun Sistem Informasi UMKM Dagang dengan MS Access.Jakarta: Elex Media Komputindo.

Warsono, Sony. Endra Mukti. Aryad Ridha. Arif Darmawan. Akuntansi UMKM Ternyata Mudah Dipahami dan Dipraktikan. Yogyakarta: Asgard Chapter 